Cuadernos de Filología Clásica. Estudios Latinos

ISSN: 1131-9062

http://dx.doi.org/10.5209/CFCL.62529

\title{
¿Matías Sánchez traductor de Lucrecio?
}

\author{
Manuel Molina Sánchez ${ }^{1}$
}

Recibido: 27 de abril de 2018 / Aceptado: 8 de noviembre de 2018

Resumen. Las traducciones de Lucrecio en España anteriores al siglo XX han sido muy escasas, hasta el punto de que puede afirmarse sin reparo que no ha habido un acercamiento profundo al poeta epicúreo en nuestro país hasta el siglo pasado. Tras un breve repaso a las versiones castellanas de los siglos XVIII y XIX, se analiza la traducción manuscrita de Matías Sánchez (1832) y su vinculación con la del abate Marchena (1791).

Palabras clave: Lucrecio en España; Matías Sánchez; abate Marchena.

\section{[en] Matías Sánchez Lucretius translator?}

\begin{abstract}
The translations of Lucretius in Spain before the twentieth century have been very scarce, to the point that it can be stated without hesitation that there has not been a deep approach to the epicurean poet in our country until the last century. After a brief review of the Spanish versions of the eighteenth and nineteenth centuries, the manuscript translation of Matías Sánchez (1832) and its connection with that of the Abbe Marchena (1791) is analyzed.
\end{abstract}

Keywords: Lucretius in Spain; Matías Sánchez; Abbe Marchena.

Cómo citar: Molina Sánchez, M., «¿Matías Sánchez traductor de Lucrecio?», Cuad. Filol. Clás. Estud. Lat. 38.2 (2018), 345-353

Que el poema De rerum natura de Lucrecio encontró siempre trabas para su difusión nadie lo pone en duda. Que la causa principal de tal impedimento fue ya en la Antigüedad una irrupción inadmisible en el pensamiento y en la moral de la época es algo evidente, si consideramos el extraño comportamiento manifestado por sus contemporáneos. ¿Por qué -se pregunta Greenblatt en la «Presentación» a la última reedición del Lucrecio de Valentí Fiol en la editorial Acantilado- la ausencia de noticias sobre Lucrecio en un mundo, la Roma del siglo I, lleno de curiosidad literaria, de rivalidades y murmuraciones, pese a la notoriedad de su nombre y de su destinatario? «La respuesta (si no se reduce todo a que ha sobrevivido por obra del azar solo aquello de lo que disponemos) puede hallarse en el hecho de que el poema se sitúa en una relación tensa y contrapuesta frente a los valores romanos básicos de la época» $(2012,6)$.

Pero donde se manifiesta más a las claras esta marginación es en la tradición cristiana occidental. Pese a su revitalización en el Renacimiento italiano, su acogida más

Universidad de Granada.

mmolina@ugr.es 
o menos tardía en países como Francia, Inglaterra y Alemania, Lucrecio siempre ha sido un poeta damnatus $\mathrm{y}$, desde esta perspectiva, su discurso puede definirse como fisura ideológica, como quebranto moral en el pensamiento dominante occidental.

En cuanto a nuestro país, si hay una nación en Occidente que haya estigmatizado especialmente a Lucrecio, esa es España. Dijimos en otro lugar que «la España feudal y sacralizante ha impuesto su hegemonía ideológica prácticamente hasta finales del siglo XX» (Molina Sánchez 2007, 313). O como aclara con más precisión García Calvo (1997, 18):

Otra muestra, más anecdótica, de los impedimentos que, desde arriba, han debido pesar sobre la lectura y transmisión de este poema a lo largo de los tiempos nos la ofrece el caso de esta desventurada patria: dominada largos siglos por el miedo y la miseria que la necesidad de un Imperio Católico hubo de imprimirles a sus almas, no tengo noticia de que en todos ellos se leyera en España el poema de Lucrecio (ni siquiera en la balumba de papeles que se han publicado de persona tan erudita como Quevedo encuentro referencia alguna), ni la hay, desde luego, de ninguna edición ni traducciones [...]: había que esperar a que, a finales del s. XVIII, el abate Marchena, salido de tierra y envuelto en intrigas con Marat y contra Marat, escribiera su traducción ${ }^{2}$, que no se publicó, además, hasta que lo hiciera Menéndez Pelayo (en edición, todavía, para bibliófilos, que no llegara a manos del gran público) con las otras obras de Marchena, en dos tomos (1892 y 1896 el segundo, donde está el Lucrecio), por los mismos años que se publicaba, en 1893, la honesta traducción en prosa de Manuel Rodríguez-Navas, prologada por don Francisco Pí y Margall.

Del mismo cariz son las opiniones de García Armendáriz (2002, 107):

Esta pobreza en traducciones de Lucrecio no se debe seguramente a desinterés o incompetencia por parte de los latinistas españoles, sino, dejando de lado un cierto raquitismo endémico de nuestro humanismo, a los inconvenientes que planteaba la difusión de una obra contraria a la ortodoxia católica en un país sometido a la censura inquisitorial y al poder de la Iglesia.

Cierto es que las indagaciones de Traver Vera, culminadas en su Tesis Doctoral aún inédita (2009), están siendo productivas en este sentido, pero la realidad es que no ha habido un acercamiento más profundo a nuestro filósofo hasta la traducción del abate Marchena que menciona García Calvo. Existe, no obstante, una versión en prosa en un manuscrito de 1785 -anterior por tanto a la traducción de Marchena-, obra de Santiago Sáez, rey de armas de su Majestad ${ }^{3}$, conservado en la Biblioteca Nacional de Madrid (ms. 5828). De él Menéndez Pelayo dice únicamente que era «tío del historiador de Madrid Álvarez Baena» (1892, n. 9), al tiempo que informa allí mismo de otras traducciones parciales publicadas hasta la fecha: fragmentos bastante extensos de una traducción en verso del ilustre marino y astrónomo D. Gabriel

En 1791.

Según el DRAE, «especialista en heráldica cuyo oficio consiste en conocer y ordenar los blasones y las genealogías de las familias nobles». 
Ciscar en sus Ensayos Poéticos (Gibraltar, 1825) cida por D. Alberto Lista (Poesías, eds. de 1822 y 1837); la versión de D. Javier de Burgos, desaparecida con otros manuscritos suyos en Granada el año 1814; y la versión en prosa de D. Manuel Rodríguez-Navas (Madrid, 1892). A ellas habría que añadir la de Matías Sánchez, transmitida en un manuscrito de 1832, conservado en la Biblioteca del Palacio Real de Madrid.

Esto significa que prácticamente hasta el siglo XX no se ha abordado en serio la necesidad de conocer a Lucrecio en nuestra lengua. De hecho, la primera traducción completa impresa es la mencionada de Rodríguez-Navas en 1892.

De todas estas aproximaciones nos hemos ocupado, de manera más o menos extensa, en una ponencia presentada recientemente en el Congreso organizado en homenaje al profesor Juan Francisco Alcina (Molina Sánchez 2017). Pero habíamos dejado para un tratamiento más exhaustivo la versión de Matías Sánchez por su singularidad.

Marcelino Gutiérrez del Caño, en su Catálogo de los manuscritos existentes en la Biblioteca Universitaria de Valencia (1913), al describir el $n^{\circ} 1333$, correspondiente al encabezamiento «LUCRECIO CARO, Tito» (T. II, 226), anota lo siguiente: «Existe un MS. traducción castellana de Matías Sánchez, año 1832, en la Biblioteca de S. M.». La noticia es retomada por García Armendáriz (2002, 108), con la advertencia de que no ha podido ver aún el manuscrito. A su vez, Traver Vera $(2009,567)$ agradece a García Armendáriz el dato, localiza el manuscrito en la Biblioteca del Palacio Real de Madrid $^{5}$ y reproduce la descripción del catálogo de la Biblioteca. La reproducimos nosotros también aquí:

Lucrecio: Sobre la naturaleza de las cosas / traducido por M[atías] S[ánchez] P. Publicación: s. XIX (1810-1832). Descripción: [1] h.+207 f.+[28] h. : papel ; 210x150 mm. ; + carta original, (300×218 mm.). Títulos uniformes: De rerum natura. Español . Contenido: h. [1]r-v: [Carta autógrafa de J. Ma . Cambronero, secretario de la Real Academia Greco-Latina, dirigida a D. Matías Sánchez, en la que elogia la traducción de Lucrecio y, por su literalidad, recomienda que no se publique. Madrid, 29 de diciembre de 1832. Firmada y con sello estampado de 1832] f. 1r: [Fragmento tomado de las Confesiones de San Agustín] f. 1v: A los estudiosos. f. 201r-207r: Notas.

La carta autógrafa a la que se alude en esta catalogación está anexada en las guardas del libro y dice así:

Don José Mª Cambronero, Doctor en leyes por la R. Universidad de Alcalá de Henares, Abogado de los R. Consejos, y Secretario de la R. Academia Greco-Latina: Certifico $^{6}$ : Que habiéndose presentado à esta R. Academia por su digno individuo D. Matías Sánchez ${ }^{7}$ una traducción del Lucrecio, poeta latino, para que se imprimiese, la ha reconocido prolijamente ${ }^{8}$ y admirando el esmero con que está

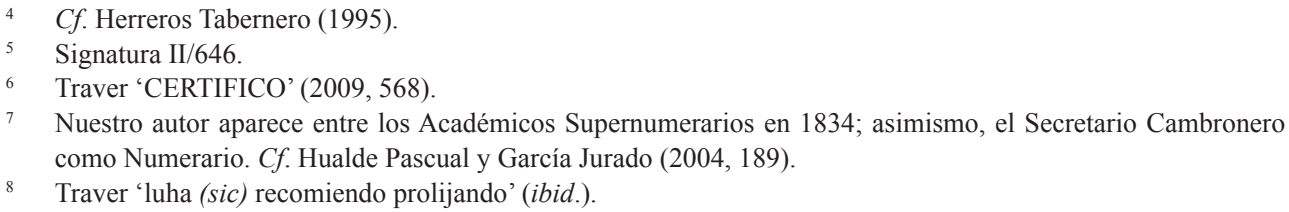


verificada $^{9}$ por la inmensa dificultad que opone la irregularidad del testo ${ }^{10}$ y la oscuridad de algunos conceptos, por lo que no pudo ${ }^{11}$ menos de alabar la laboriosidad y diligencia del traductor; pero reflecsionando ${ }^{12}$ que si se publicase ${ }^{13}$ del modo literal con que ha sido concebida ${ }^{14}$ se haría demasiado vulgar, cayendo en manos inespertas y poco preparadas para resistir a los principios arriesgados que sienta el autor, acordó esta R. Academia que se devolviese la obra con este elogio y observaciones à quien la había presentado ya para su satisfacción, ya también para que hiciese de ella el uso más conveniente. Madrid veinte y nueve de Diciembre de mil ochocientos treinta y dos. José $\mathrm{M}^{\mathrm{a}}$. Cambronero.

Pues bien, en opinión de Traver, Matías Sánchez debió de ser un «jesuita progresista» $(2009,572)^{15}$. Representaría en ese caso -añadimos nosotros- la asimilación «a lo cristiano» de la propuesta lucreciana, como ya antes S. Agustín, S. Jerónimo, Arnobio y Lactancio lo habían sugerido, o como más tarde la monja Rosvitha lo haría con las comedias de Terencio. Pero, como puede presumirse, la de los Padres de la Iglesia era una asimilación muy sesgada:

Era de esperar que Lucrecio provocara los ataques de la apología cristiana. Pero hay poco de tal cosa. Exhibía el epicureísmo cierto espíritu de austeridad y renuncia que atrajo a los ascetas cristianos [...] Se da una paradójica comunidad de sentimientos. Incluso en Lucrecio buscan los autores cristianos argumentos para desacreditar los cultos paganos. Es un desguace de ideas con fines apologéticos. (Socas 2003, 63).

Se entiende, con todo, que es una utilización consciente y parcial:

Estos contactos leves no deben hacer olvidar que epicureísmo y cristianismo son antitéticos [...] Cuando el cristianismo gana la batalla y se establece en todas partes, remite el fervor polémico antipagano y Lucrecio se queda en el limbo de los tratadistas de retórica, los gramáticos y lexicógrafos, que llevan a cabo un troceo del De rerum natura con fines eruditos y escolares. (Socas 2003, 64).

Esa sería, pues, la lectura que podría esperarse de Matías Sánchez sobre Lucrecio, la de una adaptación al pensamiento cristiano de los postulados más acordes con el cristianismo del poeta latino, si hubiese motivos serios para pensar que Matías Sánchez fue jesuita. Pero los argumentos esgrimidos por Traver al respecto son muy poco convincentes. Dice a propósito $(2009,572$, n. 268):

\footnotetext{
Traver 'versificado' (ibid.).

Traver 'texto' (ibid.).

Traver 'puedo' (ibid.).

Traver 'reflexionando' (ibid.).

Traver 'publicara' (ibid.).

Traver 'concebido' (ibid.).

Sobre las imitaciones pedagógicas de Lucrecio llevadas a cabo por la Compañía de Jesús, cf. Socas (2003, 75

S.).
} 
La P. en su época era la abreviatura común de "Padre" y en la protesta de su traducción ${ }^{16}$ Jesucristo ocupa un lugar principal, por lo que parece claro que era religioso. Debió de ser, además, jesuita, pues el último verso de la misma ("Sin temer el furor de los tiranos") ataca a los tiranos, y uno de los postulados más polémicos que defendieron los jesuitas en su tiempo fue precisamente la legitimidad del pueblo para cometer tiranicidio.

A nuestro modo de ver, sin embargo, la P. de las iniciales M. S. P. que aparecen en el título del libro (Lucrecio. Sobre la Naturaleza de las cosas. Traducido por M. S. $P$.) no tiene por qué referirse a 'Padre', más bien parece aludir a un segundo apellido. Es más, P. como abreviatura por 'Padre' suele encontrarse al principio del nombre, no al final. De hecho, como puede apreciarse en las reproducciones de arriba, ni en la descripción catalográfica del manuscrito, ni en la carta de Cambronero se menciona para nada la condición religiosa del autor. En esta última incluso no se dice el 'P. Matías Sánchez', sino 'D. Matías Sánchez'. En cuanto a la apelación a Jesucristo y al tiranicidio, no nos parecen argumentos determinantes.

Pero lo que resulta más sorprendente de todo este tema es que un investigador como Traver, que ha dedicado su Tesis al estudio de la presencia de Lucrecio en España, no se haya percatado de que la traducción en verso que Matías Sánchez ofrece de Lucrecio no es suya, sino del abate Marchena. Y sorprende en un doble sentido: primero porque una comparación simple de cualquier pasaje delata este extremo y, segundo, porque Traver comenta varios fragmentos de ambos autores sin inmutarse, convencido incluso de que la versión de Marchena es muy superior a la de Sánchez ${ }^{17}$. A su vez, esta es también una prueba -creemos nosotros- del distanciamiento de Matías Sánchez del credo religioso jesuita, pues difícilmente un Padre de la Compañía asumiría hasta el punto de plagiarlo el discurso de un anticlerical afrancesado practicante y confeso como el abate Marchena.

Asombroso resulta también que el Secretario de la R. Academia Greco-Latina, José $\mathrm{M}^{\mathrm{a}}$. Cambronero, un hombre instruido, o la propia Academia, no reconocieran la mano de Marchena en la traducción de Matías Sánchez. Ello indica, por un lado, que el texto de Marchena gozaba de influencia suficiente como para, sin haber sido editado, circular manuscrito entre los eruditos cuarenta años después de su elaboración; pero, por otro, que su divulgación debió de ser muy limitada, pues no era identificado fácilmente.

¿En qué consistió entonces el trabajo de Sánchez? Pues aparte de unos cambios mínimos en la traducción, en la inclusión de pequeños resúmenes en prosa al co-

\footnotetext{
Véase infra el poema 'A los estudiosos'.

17 Dice así de la traducción de Marchena (2009, 563): «En líneas generales, la versión de Marchena es elegante y clara, fiel al texto y al sentido. Tiene el mérito indiscutible de estar en verso como el original y de reintegrar la mayor parte de las figurae que hacían sublime la poesía de Lucrecio. Resulta, en este sentido, una aemulatio, pues imita dentro de sus posibilidades el decoro propio del poeta. En resumidas cuentas, Marchena culminó una versión poética, que nada debe envidiar a las ya clásicas de Creech, Marchetti o La Grange». En cambio, de la de Sánchez manifiesta lo siguiente $(2009,574)$ : «Según esta cata, la versión de Matías Sánchez resulta, en líneas generales, pedestre y prosaica. Sus endecasílabos carecen de la elegancia poética exigible a una traducción en verso, por lo que, alineados en párrafos, quizás defraudaran menos. Y, aunque la excusa principal del Secretario de la Academia Greca-Latina para no otorgar el imprimatur fuera el perjuicio moral que causaría su lectura en los jóvenes, es probable que pesara también el modo literal y vulgar en que la compuso. Matías Sánchez acometió en su labor traductora las fases de immutatio e interpretatio, pero se olvidó casi por completo de trasladar el ropaje retórico»》.
} 
mienzo de cada libro y la adición, al final de cada uno, de unas notas sobre aquellos pasajes lucrecianos que, a su juicio, merecían alguna aclaración. Prevalecen aquí las explicaciones de temas científicos, sin descuidar el tratamiento de asuntos más estrictamente filosóficos. Ello induce a pensar que nuestro autor estaba más interesado en la divulgación científica que en el contenido más puramente ideológico. Y es esta parte, la de las notas, la única, propiedad de Sánchez, en la que, además, el académico se esfuerza en dejar constancia de sus conocimientos, pues los resúmenes introductorios son meras indicaciones orientativas.

Pondremos dos ejemplos para ilustrar lo que decimos. El primero es relativo a la traducción. Compárese el inicio del libro II en ambos autores ${ }^{18}$ :

\section{Marchena}

Revolviendo los vientos las llanuras del mar, es deleitable desde tierra contemplar el trabajo grande de otro; no porque dé contento y alegría ver a otro trabajado ${ }^{19}$, más es grato considerar los males que no tienes; suave también es sin riesgo tuyo mirar grandes ejércitos de guerra en batalla ordenados por los campos; pero nada hay más grato que ser dueño de los templos excelsos guarnecidos por el saber tranquilo de los sabios, desde do puedas distinguir a otros y ver cómo confusos se extravían y buscan el camino de la vida vagabundos, debaten por nobleza, se disputan la palma del ingenio, y de noche y de día no sosiegan por oro amontonar y ser tiranos. ¡Oh míseros humanos pensamientos! ¡Oh pechos ciegos! ¡Entre qué tinieblas $\mathrm{y}$ a qué peligros exponéis la vida, tan rápida, tan tenue! ¿Por ventura no oís el grito de naturaleza, que alejando del cuerpo los dolores, de grata sensación el alma cerca, librándola de miedo y de cuidado?

\section{Sánchez}

Revolviendo los vientos las llanuras Del mar, es deleytable desde tierra Contemplar el trabajo grande de otro; No porque de contento y alegría Ver a otro trabajado; mas es grato Considerar los males que no tienes: Suave tambien es sin riesgo tuyo Mirar grandes egercitos de guerra En batalla ordenados por los campos:

Pero nada hay más grato que ser dueño De los templos escelsos guarnecidos Por el saber tranquilo de los sabios, Desde do puedas distinguir a otros, Y ver como confusos se estravian Y buscan el camino de la vida Vagabundos, debaten por nobleza, Se disputan la palma del ingenio, $\mathrm{Y}$ de noche y de dia no sosiegan Por amontonar oro, y ser tiranos. O miseros humanos pensamientos! O pechos ciegos! entre que tinieblas $\mathrm{Y}$ a que peligros esponeis la vida, Sus rapidos instantes! Por ventura No ois el grito de Naturaleza, Que alejando del cuerpo los dolores De grata sensacion el alma cerca, Librandola de miedo y de cuidado?

\footnotetext{
18 Seguimos para Marchena el texto editado por Menéndez Pelayo (1896); en cuanto a Sánchez, el fragmento se encuentra en ff. 39rv.

19 En García Calvo $(2007,139)$ 'trabajando'.
} 
Este es el tenor general de toda la obra: idéntica traducción con ligeras modificaciones casi imperceptibles. Cualquier pasaje que escojamos sigue el mismo esquema.

Veamos ahora la nota final aclaratoria correspondiente al segundo hemistiquio del verso 1,330 Namque est in rebus inane (ff. 33v-34r):

Se puede considerar el espacio como privado de cuerpo, como ocupado por un cuerpo, o como corrido por un cuerpo. En el primer caso se llama vacio; en el segundo, lugar; en el tercero, region. Sesto Empirico nos da esta definicion tan necesaria para la inteligencia de la famosa cuestion del vacio. La primera cuestion que se nos propone es si mas alla del Universo hay vacio; sobre lo cual no hay disputa, porque los que tenian al Universo como un todo limitado, se veian precisados a confesar un espacio vacio de todo cuerpo. Al contrario, los que no le ponian limites, no podian admitir un espacio ulterior. La segunda cuestion es si en el mismo Universo hay pequeños intersticios vacios diseminados en todos los cuerpos. Aquí esta toda la dificultad, pero hace tan poco al caso, que aun los mismos Atomistas defendian el pro y el contra. Al fin por mas que se dispute, todo sera hipotetico: ocupense las Escuelas en estas sutilezas.

Desde otra perspectiva, la ideológica, Matías Sánchez representa esa visión mixta, entre cristianismo y materialismo, de aceptación del hecho científico sin abandono del ideal cristiano; una concepción por tanto que refleja las contradicciones y múltiples caras del fenómeno literario. Eso es al menos lo que para nosotros significa la fusión sin ambages en una misma obra de dos pensamientos antagónicos: la traducción de un revolucionario como Marchena por un lado, y por otro, la cita de las Confesiones de San Agustín (6,16,26), con que el autor encabeza su obra, junto con la alusión al Santo y a Jesucristo como salvador con que prologa su libro en estos versos dedicados 'A los estudiosos' (f. 1v):

Solo a vosotros, hombres estudiosos,

Dedico los escritos de este sabio,

De aquel varon romano, cuyos labios

La divina natura sublimaron

Esplicando sus obras admirables.

De mi pecho triunfava $\sin ^{20}$ disputa,

Dice el grande Agustino, la doctrina

Del filosofo griego, si no fuera

Por sentar que perecen nuestras almas,

Y que no hay galardon en la otra vida,

Ni corona de gloria para el justo,

$\mathrm{Ni}$ castigo para hombres desalmados.

A nosotros nos basta Jesucristo;

El es nuestra salud ${ }^{21}$, nuestro consuelo;

Por el daremos toda nuestra sangre,

Su ley es dulce, facil, muy humana:

En el ponemos nuestra confianza

Sin temer el furor de los tiranos.

Traver 'mi' (2009, 572).

Traver 'salida' (ibid.). 
El plagio de Matías Sánchez, sin embargo, no se publicó, como tampoco las traducciones de sus antecesores Santiago Sáez y el abate Marchena. Solo este último llegaría a las prensas un siglo después de su redacción, como se ha dicho, gracias al entusiasmo, que no devoción, de Menéndez Pelayo por su obra. Había que esperar, pues, al siglo XX para que Lucrecio fuese editado y conocido en nuestra lengua.

\section{Referencias bibliográficas}

García Armendáriz, J.-I. (2002), «Lucrecio en la España de Fernando VII», en Lafarga, F., Palacios Bernal, C. y Saura Sánchez, A. (eds.), Neoclásicos y románticos ante la traducción, Murcia, Universidad, 103-118.

García Calvo, A. (1997), Lucrecio. De rerum natura. De la realidad, Zamora, Lucina.

- (20076 [1983]), Lucrecio. De la naturaleza de las cosas, trad. del Abate Marchena, Madrid, Cátedra.

Greenblatt, S. (2012), «Presentación», en Valentí Fiol, E., T. Lucrecio Caro. De rerum natura. De la naturaleza, Madrid, Acantilado, 5-14.

Gutiérrez del Caño, M. (1913), Catálogo de los manuscritos existentes en la Biblioteca Universitaria de Valencia, 3 v., Valencia, Librería Maraguat.

Herreros Tabernero, E. (1995), «Lucrecio y otras fuentes latinas en el Poema fisicico-astronómico de Gabriel Ciscar y Ciscar», $C F C(L)$ 8, 281-293.

Hualde Pascual, P. y García Jurado, F. (2004), «La Academia (Greco)latina matritense. Primera parte: su historia (1755-1849)», Minerva 17, 165-198.

Menéndez Pelayo, M. (1892), Obras literarias de D. José Marchena (El abate Marchena), recogidas de manuscritos y raros impresos con un estudio crítico-biográfico, T. I, Sevilla, Imp. de E. Rasco, <http://www.cervantesvirtual.com/obra/obras-literarias-de-d-jose-marchena-tomo-i--0/> [consultado 01/03/2018].

- (1896), Obras literarias de D. José Marchena (El abate Marchena), recogidas de manuscritos y raros impresos con un estudio crítico-biográfico, T. II, Sevilla, Imp. de E. Rasco, <http://www.cervantesvirtual.com/obra/obras-literarias-de-d-jose-marchena-tomo-ii--0/> [consultado 01/03/2018].

Molina Sánchez, M. (2007), «Plauto y Terencio en el Renacimiento español: la Tragicomoedia Gastrimargus de Jaime Romañá», Florllib 18, 311-331.

- (2017), «Literatura e ideología: a propósito de algunas versiones castellanas de Lucrecio», en EVROPA RENASCENS. Latín y vernáculo en los Siglos de Oro (Homenaje al profesor Juan Francisco Alcina Rovira), Congreso Internacional celebrado en Jaén-Baeza, 20 al 24 de noviembre de 2017, en prensa.

Rodríguez-Navas, M. (1892), Tito Lucrecio Caro. Naturaleza de las cosas, Madrid, Agustín Avrial.

Sáez, S. (1785), Tito Lucrecio Caro. De la naturaleza de las cosas, Madrid, ms. 5828 BNE. Sánchez, M. (1832), Lucrecio. Sobre la naturaleza de las cosas, Madrid, ms. II 646 BPR.

Socas, F. (2003), Lucrecio. La naturaleza, Madrid, Gredos.

Traver Vera, Á. J. (2009), Lucrecio en España: o la recepción de un epicúreo en la literatura española, Tesis Doctoral inédita leída el 21/9/2009. 